NBER WORKING PAPER SERIES

\title{
CONSUMPTION RISK AND EXPECTED STOCK RETURNS
}

\author{
Jonathan A. Parker \\ Working Paper 9548 \\ http://www.nber.org/papers/w9548 \\ NATIONAL BUREAU OF ECONOMIC RESEARCH \\ 1050 Massachusetts Avenue \\ Cambridge, MA 02138 \\ March 2003
}

Prepared for the AEA Papers and Proceedings. I thank Markus Brunnermeier and Monika Piazzesi for helpful comments, Christian Julliard for research assistance, and the National Science Foundation (SES-0096076) and the Sloan Foundation for financial support. The views expressed herein are those of the authors and not necessarily those of the National Bureau of Economic Research.

(C)2003 by Jonathan A. Parker. All rights reserved. Short sections of text not to exceed two paragraphs, may be quoted without explicit permission provided that full credit including Cnotice, is given to the source. 
Consumption Risk and Expected Stock Returns

Jonathan A. Parker

NBER Working Paper No. 9548

March 2003

JEL No. G12, G11, E21

\section{$\underline{\text { ABSTRACT }}$}

Following the textbook C-CAPM, the consumption risk of an asset is typically measured as the contemporaneous covariance of the marginal utility of consumption and the return on that asset. When measured this way, consumption risk is too small to explain the observed equity premium, is negatively related to expected excess returns over time, and fails to explain the cross-sectional differences in average returns of the Fama and French (25) portfolios. This paper evaluates the central insight of the C-CAPM - that consumption risk determines returns - but take the model less literally by allowing the possibility that households do not instantaneously and completely adjust consumption to the news revealed about wealth in a period. The long-term consumption risk of the aggregate market is signficantly larger than the contemporaneous risk and is positively related to expected excess returns over time. The long-term consumption risk of different portfolios largely explains the observed differences in average returns.

Jonathan A. Parker

Department of Economics

Bendheim Center for Finance

and Woodrow Wilson School of Public and International Affairs

Princeton University

Princeton, NJ 08544-1013

and NBER

jparker@princeton.edu 
US stock returns are large, predictable over time, and predictable across stocks. The average return on a diversified market portfolio has averaged eight percent per year more than the return on a short-term treasury bill. The predictability of time variation in returns is modest at high frequencies - about ten percent of the variation in returns one quarter ahead is predictable - and quite large over longer periods - just under half of the variation in returns over five year periods is predictable. Finally, portfolios based on the intersection of quintiles of stocks ranked by market value and by the ratio of book value to market value have differences in average annual returns across stocks of several percent per year.

The natural explanation for these variations in returns is risk. But variations in consumption risk have done a poor job of explaining these differences in expected returns. ${ }^{1}$ According to the canonical economic model of asset pricing, the textbook consumption capital asset pricing model (CCAPM), the risk of the market or a portfolio of stocks depends on the expected covariance of returns with consumption: (a time of) high covariance implies (a time of) high risk and thus high expected return. But after two decades of research, the consensus view is that differences in returns are not due not to variation in the covariance of aggregate consumption and returns, but are instead due to variation in effective risk aversion or to "behavioral" phenomenon such as irrational exuberance, noise trading, rules of thumb, or psychological biases.

This paper evaluates the central insight of the CCAPM - that consumption risk determines returns - but take the model less literally by allowing the possibility that households do not instantaneously and completely adjust consumption to the news revealed about wealth in a period. That is, allowing the possibility that consumption is slow to adjust, this paper measures consumption risk not as the contemporaneous covariance of a return with consumption growth - as done in the previous literature on the C-CAPM - but instead as the covariance of a return and consumption growth over the quarter of the return and many

\footnotetext{
${ }^{1}$ E.g. Sanford J. Grossman and Robert J. Shiller (1981), Shiller (1982), Lars Peter Hansen and Kenneth J. Singleton (1983), and N. Gregory Mankiw and Matthew D. Shapiro (1986).
} 
following quarters.

Long-term consumption risk is an important determinant of expected asset returns. I review and present evidence that the long-term consumption risk of equity is more than six times the contemporaneous risk, and further that the long-term consumption risk of households actually participating in the equity market is largely sufficient to rationalize the equity premium. Thus, the equity premium is matched by a model in which stockholders have reasonable levels of risk aversion and correctly assess the risks of equity when making investment decisions, but do not completely adjust consumption contemporaneously with returns.

Long-term consumption risk also helps to explain the time variation in expected returns. In theory, high expected returns occur when the expected covariance between consumption growth and innovations to the market is large. While for contemporaneous risk, the data show the reverse pattern, for long-term consumption risk, risk and expected returns are positively related. This relationship is weak however. For reasonably levels of risk aversion, consumption risk predicts far less variation in expected returns over time than observed, and the positive relationship is not robust for large instrument sets.

Finally, long term consumption risk can explain differences in cross-sectional returns. While beta's based on the contemporaneous movement of consumption and returns have almost no predictive power in explaining the pattern of average returns across portfolios, beta's based on the long-term movement of consumption are highly statistically significant in explaining average returns and explain a large fraction of the variation in average returns. I present a nonlinear version of the analysis of Jonathan A. Parker and Christian Julliard (2002) and show that the explanatory power of long-term consumption risk is as good as that of the three-factor models of Eugene F. Fama and Kenneth R. French (1993) and Martin Lettau and Sydney Ludvigson (2001). But like the equity premium, this explanation requires high levels of risk aversion. 


\section{Theory}

Following Mark Rubinstein (1976) and Douglas T. Breeden (1979), the CCAPM posits that households maximize the expected present discounted value of utility flows from consumption by allocating wealth to consumption and different investment opportunities. When households are behaving optimally, a marginal investment at $t$ in any asset should yield the same expected marginal increase in utility at $t+1$ :

$$
E_{t}\left[C_{t+1}^{-\gamma} R_{i, t+1}\right]=E_{t}\left[C_{t+1}^{-\gamma} R_{t+1}^{f}\right]
$$

where $\gamma$ is the representative household's coefficient of relative risk aversion, assumed constant, $C$ is consumption, $R_{i, t+1}$ is the gross return on asset $i$, unknown at $t$, known at $t+1$, and $R_{t+1}^{f}$ is the rate of return that is risk-free.

This equation assumes that agents instantaneously and completely adjust consumption to returns. Such an assumption is at odds with the literature on the intertemporal allocation of consumption which is in wide agreement that the simple, textbook model of a representative consumer is false and that consumption displays excess smoothness in response to wealth shocks. ${ }^{2}$ There is not agreement about the correct alternative model, and contenders include: marginal utility of nondurable consumption not being additively separable from factors that are subject to frictions (such as leisure, housing, or external habits); uninsurable idiosyncractic risk or borrowing constraints; direct adjustment costs on consumption; mismeasurement in consumption data; informational or calculation constraints on agents.

Instead of making this assumption, I measure the consumption risk of an investment by

\footnotetext{
${ }^{2}$ The slow adjustment of consumption has a long history starting with Marjorie Flavin (1981) and Robert E. Hall and Frederic S. Mishkin (1982). Even the seminal paper, Hall (1978), which first notes that consumption should not be slow to adjust rejects the random walk of consumption using data on market returns.
} 
its risk to consumption $S$ periods in the future:

$$
E_{t}\left[C_{t+1+S}^{-\gamma} R_{i, t+1}\right]=E_{t}\left[C_{t+1+S}^{-\gamma} R_{t+1}^{f}\right]
$$

This measure, for large $S$, has several appealing features. First, this approach maintains the assumption that the primary determinant of utility is the level of flow consumption. Second, this approach is consistent with the canonical model of portfolio choice in that the ultimate risk and the contemporaneous risk should be approximately the same according to the canonical model (exactly the same if the risk free rate is constant). Third, and most importantly, this approach provides a better measure of the true risk of the stock market under a wide class of extant models used in the study of household consumption and saving. Parker (2001) and Parker and Julliard (2002) show in a set of models that if households choose their portfolios at time $t$ and consumption responds with a lag to changes in wealth, then this measure provides a superior measure of the consumption risk of an asset while the contemporaneous covariance of consumption and returns understates this risk. ${ }^{3}$ Thus, this measure allows us to evaluate the economic insight that consumption risk should determine returns even though the true or complete model of household saving and portfolio choice has to date escaped discovery.

To fit the model to the observations on returns discussed in the introduction, divide equation (1) by marginal utility in $t$ to move from the nonstationary $C_{t+1+S}^{-\gamma}$ to the stationary $\left(C_{t+1+S} / C_{t}\right)^{-\gamma}$. To model the equity premium, consider the risky asset to be the market return, $R_{t+1}$, take the unconditional expectation, and use the definition of the covariance to

\footnotetext{
${ }^{3}$ These papers consider the textbook model; a modification in which the marginal utility of consumption is shifted by a stationary variable that covaries with returns; a model in which constraints on information flow slow consumption movements; and finally the impact of the fact that aggregate consumption contains serially correlated measurement error due to the use of lagged data in its construction. Under some models, the risk aversion implied by this measure provides an upper bound on the true risk aversion of the agent.
} 
get

$$
E\left[R_{t+1}-R_{t+1}^{f}\right]=-\frac{\operatorname{Cov}\left[\left(C_{t+1+S} / C_{t}\right)^{-\gamma}\left(R_{t+1}-R_{t+1}^{f}\right)\right]}{E\left[\left(C_{t+1+S} / C_{t}\right)^{-\gamma}\right]}
$$

The implications for time variation in returns over time follow from the same steps without taking the unconditional expectation

$$
E_{t}\left[R_{t+1}-R_{t+1}^{f}\right]=-\frac{\operatorname{Cov}_{t}\left[\left(C_{t+1+S} / C_{t}\right)^{-\gamma}\left(R_{t+1}-R_{t+1}^{f}\right)\right]}{E_{t}\left[\left(C_{t+1+S} / C_{t}\right)^{-\gamma}\right]}
$$

Finally, to compare returns across stochastic assets, the derivation with the unconditional expectation for any asset gives the beta representation:

$$
E\left[R_{i, t+1}-R_{t+1}^{f}\right]=\alpha+\beta_{i, S} \lambda_{S}
$$

where

$$
\alpha=0, \beta_{i, S}=\frac{\operatorname{Cov}\left[\left(C_{t+1+S} / C_{t}\right)^{-\gamma},\left(R_{i, t+1}-R_{t+1}^{f}\right)\right]}{\operatorname{Var}\left[\left(C_{t+1+S} / C_{t}\right)^{-\gamma}\right]}, \lambda_{S}=-\frac{\operatorname{Var}\left[\left(C_{t+1+S} / C_{t}\right)^{-\gamma}\right]}{E\left[\left(C_{t+1+S} / C_{t}\right)^{-\gamma}\right]}
$$

This is a linear factor model with a single factor, consumption risk. The paper now evaluates each of these implications in turn.

\section{The equity premium}

Real chain-weighted consumption expenditures on nondurable goods per capita are used as the measure of consumption. Market returns are value-weighted NYSE real returns and the risk-free rate is proxied by the return on a three-month treasury bill. $R_{t+1}$ and $R_{t+1}^{f}$ are returns during $t+1$, so that $C_{t}$ is completely prior to the return. The intersection of the series and allowing for a reasonable horizon $(S)$ determines the sample of returns: 1947 second quarter to 1998 first quarter. 
The average return on the stock market over this period is 2.5 percent per quarter and the average premium over this period is 2.0 percent per quarter. The equity premium puzzle (Rajnish Mehra and Edward C. Prescott (1985)) is that the contemporaneous covariance of consumption risk and market returns is far too small to rationalize this high average return. For $S=0$ and assuming a plausible level of risk aversion of five, the right-hand side of equation (2) predicts an equity premium of 0.037 percent per quarter, or one sixtyeighth of the actual premium. All three terms in equation (2) are measured with error - the average equity premium, the covariance, and the average growth in marginal utility - but the economic magnitude of this gap is huge.

Figure 1 plots the implied equity premium for different levels of risk aversion (horizontal axis) and different horizons ( $S$ as different lines). The solid and lowest line is the implied premium for $S=0$ and demonstrates the magnitude of the puzzle for contemporaneous consumption risk. More importantly, as the horizon is increased to $S=1,3$, and 7, measured consumption risk rises uniformly and the equity premium becomes less of a puzzle. For $\gamma=5$ the implied premium is 0.24 percent at a horizon of two years $(S=7)$, more than 6 times that implied by the contemporaneous consumption risk. ${ }^{4}$

But while measured consumption risk is substantially higher allowing for the slow adjustment of consumption, it is still an order of magnitude too small to be consistent with the historical equity premium. The average equity premium less two standard deviations is 1.1 percent, or roughly the top of Figure 1. Further, the long-term consumption risk begins to decline after two years; for a three-year horizon $(S=11$, the finely dashed line), and $\gamma=5$, the consumption risk of the stock market implies a premium of only 0.15 , similar to that at $S=3$. While the decline in measured consumption risk after some period would seem consistent with slow consumption adjustment in response to the time-series correlation

\footnotetext{
${ }^{4}$ This result appears in a linearized form in Xavier Gabaix and David Laibson (2001), Monika Piazzesi (2001), Parker (2001), and these papers also review the previous theoretical literature (most notably Anthony W. Lynch (1996) and David A. Marshall and Nayan G. Parekh (1999)).
} 
of returns (poor returns following a run of goods returns), this depends on the model and raises the puzzle of the time series variation in returns addressed in the next section.

So is the consumption risk of equity is too small? Yes in aggregate. But following Mankiw and Stephen P. Zeldes (1991), Annette Vissing-Jorgensen (1998) argues that consumption risk in aggregate data is plausibly biased downwards by a factor of 6 due to limited participation in the stock market. Yacine Ait-Sahalia, Parker, and Motohiro Yogo (2001) and Orazio Attanasio and Vissing-Jorgensen (2003) show that contemporaneous measures of the consumption risk of rich households imply more plausible levels of risk aversion. Parker (2001) shows that this is even more true for the long-term consumption risk. The long-term consumption risk of the stock market for the subset of households in the Consumer Expenditure Survey that hold equity predicts an equity premium statistically close to the historical average. Thus the equity premium is consistent with the optimizing model of portfolio choice embedded in the CCAPM for stockholders, particularly once one examines the actual longterm risk that equity presents for household consumption. The question for understanding the equity premium is what keeps some households out of the stock market.

\section{The time variation in expected returns}

The optimal portfolio behavior by households implies that returns should on average be higher in periods in which the consumption risk (or long-term consumption risk) of the stock market is greater. To evaluate this basic insight, let $\gamma=5$ and run a pair of linear regressions of $\left(C_{t+1+S} / C_{t}\right)^{-\gamma}$, and $R_{t+1}-R_{t+1}^{f}$ on a set of variables that are known to be

useful in predicting returns and consumption: $C_{t} / C_{t-1},\left(R_{t}-R_{t}^{f}\right), R_{t}$, and the ratio of the last four quarters of dividends to the equity price at the end of $t$. The predicted values from these regression are the left-hand side of equation (3) and the denominator of the right-hand side. To construct the conditional covariance, the innovations to returns and the ratio of marginal utilities are multiplied and again predicted using the same linear regression. From 
the perspective of statistical inference, this procedure is useless, but from the perspective of economic inference, it is transparent.

Panel $A$ of Figure 2 presents a scatter plot of each quarters expected excess returns on the vertical axis and the consumption risk, $\frac{\operatorname{Cov}_{t}\left[\left(C_{t+1} / C_{t}\right)^{-\gamma}\left(R_{t+1}-R_{t+1}^{f}\right)\right]}{E_{t}\left[\left(C_{t+1} / C_{t}\right)^{-\gamma}\right]}$ on the horizontal axis (note $S=0$ ). Theory (equation $(3)$ ) predicts that returns should lie on the 45 degree line, the solid line in Figure 2. In fact, there is a steep negative relationship in the data. The dashed line is the regression line of the left-hand side of equation (3) onto the right-hand side. While it is well known that expected returns are far more variable than predicted by the CCAPM, it is also the case that times of high consumption risk are associated with lower, not higher, returns.

Panel $B$ of Figure 2 presents the same information for long-term consumption risk with a horizon of 11 . While increased noise in the stochastic discount factor leads to increased variation in the measure of expected consumption risk, the relationship between risk and expected returns for $S=11$ is positive. That is, times of high long-term consumption risk are times of high expected returns. ${ }^{5}$ The role of long-term consumption risk is limited however. There is far more variability in expected returns than is consistent with variations in expected consumption risk. Similar to the case of the equity premium, higher levels of assumed risk aversion can amplify the predicted variation in expected returns and can reduce a simple regression line to the 45 degree line.

In sum, while greater contemporaneous consumption risk does not imply higher expected excess returns, greater long-term consumption risk does. On the other hand, the magnitude of variation in expected returns is hard to explain with reasonable levels of risk aversion, and instead suggests time-variation in effective risk aversion or investor psychology.

\footnotetext{
${ }^{5}$ There is some variation by horizon and choice of instruments. Shorted horisons and larger instrument sets can reverse the sign of the correlation.
} 


\section{The cross-section of expected stock returns}

This section recasts the main results of Parker and Julliard (2002) and demonstrates that long-term consumption betas explain the cross-section of returns, but only for high assumed levels of risk aversion.

Figure 3 plots the average real quarterly returns for the Fama and French (1992) (25) portfolios (vertical axis) against the consumption betas as defined in equation (4) (horizontal axis) and again assuming $\gamma=5$. Each portfolio is denoted by the relative size (1 to 5$)$ and relative book to market ratio ( 1 to 5$)$. The sample is matched to that used in Lettau and Ludvigson (2001). ${ }^{6}$

Panel $A$ shows the well-known lack of relationship between average returns and contemporaneous $(S=0)$ consumption betas. The lower solid line plots equation (4) using the theoretical value $\alpha=0$ and the empirical counterparts to the theoretical moments to calculate $\lambda_{0}$. Consumption risk predicts returns that are much smaller than all those observed the equity premium puzzle again. The higher solid line chooses $\alpha$ to best fit the data and emphasizes how little variation in average returns is predicted by the model. Finally, we can ask whether there is any relationship between consumption betas and returns. A regression line has the correct slope, but is statistically insignificant: $\hat{\lambda}_{0}=-0.0237(0.0149)$.

Panel $B$ shows that long-term consumption risk at a horizon $(S)$ of three years has large explanatory power, but does not match the equity premium or the spread in returns for plausible levels of risk aversion. ${ }^{7}$ As in Panel $A$, the lower solid line maps out the predicted return as a function of beta based on $\alpha=0$ and $\lambda_{S}$ constructed from the empirical counterparts to the theoretical moments. It again predicts very low returns. Choosing $\alpha$ to

\footnotetext{
${ }^{6}$ In this sample, consumption risk fits returns with a higher fit than in larger sample. But a longer sample yeilds the same relative fit of consumption risk for $S=11$, consumption risk for $S=0$, and the Fama and French and Lettau and Ludvigson models.

${ }^{7} S=11$ is the largest $\mathrm{S}$ that maintains a low ratio of estimation error to the cross-sectional variation of the betas, as discussed in Parker and Julliard (2002). $S=11$ also maximizes the fit of the regression and so is chosen by a Bayesian model selection criterion.
} 
best fit returns, the model predicts more spread in returns than for contemporaneous risk, but still far less than observed in the data.

That said, long-term consumption betas can explain the majority of the variation in returns. The dash line in Panel $B$ is the regression line of consumption betas on returns. The line is highly statistically significant: $\hat{\lambda}_{0}=-0.168(0.078)$. It is also highly economically significant. This one factor, long-term consumption risk, explains 72 percent of the variation across portfolios. This explanatory power matches that of the three factor models of Fama and French (1993) and Lettau and Ludvigson (2001). The divide between the theoretical and regression lines in Panel $B$ of Figure 3 can be closed by assuming a higher level of risk aversion. That is, high levels of risk aversion can align the theoretical and "best fit" slopes, and, as for the equity premium, bring the model and data into alignment.

In sum, consumption risk explains the cross-sectional variation in average returns. But, as for aggregate returns, this explanation requires high levels of risk aversion. It remains an interesting question whether the long-term consumption risk of stockholders does in fact explain the cross-section of returns and whether constraints that limit participation can mimic high risk aversion in this setting. 


\section{References}

Ait-Sahalia, Yacine, Jonathan A. Parker, and Motohiro Yogo, "Luxury Goods and the Equity Premium," Aug 2001. NBER Working Paper 8417.

Attanasio, Orazio and Annette Vissing-Jorgensen, "Stock Market Participation, Intertemporal Subsititution and Risk Aversion," American Economic Review (Papers and Proceedings), May 2003.

Breeden, Douglas T., "An Intertemporal Asset Pricing Model with Stochastic Consumption and Investment Opportunities," Journal of Financial Economics, 1979, 7, 265-96.

Fama, Eugene F. and Kenneth R. French, "The Cross-Section of Expected Stock Returns," The Journal of Finance, Jun 1992, 47, 427-465.

— and - , "Common Risk Factors in the Returns on Stocks and Bonds," The Journal of

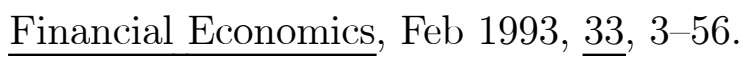

Flavin, Marjorie, "The Adjustment of Consumption to Changing Expectations about Future Income," Journal of Political Economy, 1981, 89, 974-1009.

Gabaix, Xavier and David Laibson, "The 6D bias and the equity premium puzzle," in Ben Bernanke and Ken Rogoff, eds., N.B.E.R. Macroeconomics Annual 2001, Cambridge: MIT Press 2001, pp. 257-311.

Grossman, Sanford J. and Robert J. Shiller, "The Determinants of the Variability of Stock Market Prices," American Economic Review (Papers and Proceedings), May 1981, 71 (2), 222-27.

Hall, Robert E., "The Stochastic Implications of the Life Cycle Permanent Income Hypothesis," Journal of Political Economy, 1978, $\underline{86}$ (6), 971-87.

- and Frederic S. Mishkin, "The Sensitivity of Consumption to Transitory Income: Estimates from Panel Data on Households," Econometrica, 1982, 50, 461-481.

Hansen, Lars Peter and Kenneth J. Singleton, "Stochastic Consumption, Risk Aversion, and the Temporal Behavior of Asset Returns," Journal of Political Economy, 1983, 91, 
$249-68$.

Lettau, Martin and Sydney Ludvigson, "Resurrectiong the (C)CAPM: A Cross-Sectional Test When Risk Premia Are Time-Varying," Journal of Political Economy, 2001, 109, $1238-1286$.

Lynch, Anthony W., "Decision Frequency and Synchronization Across Agents:

Implications for Aggregate Consumption and Equity Return," Journal of Finance, Sep 1996, 51 (4), 1479-97.

Mankiw, N. Gregory and Matthew D. Shapiro, "Risk and Return: Consumption Beta Versus Market Beta," Review of Economics and Statistics, Aug 1986, 68, 452-59.

- and Steven Zeldes, "The Consumption of Stockholders and Nonstockholders," Journal of Financial Economics, Mar 1991, 29 (1), 97-112.

Marshall, David A. and Nayan G. Parekh, "Can Costs of Consumption Adjustment Explain Asset Pricing Puzzles?," Journal of Finance, Apr 1999, 54 (2).

Mehra, Rajnish and Edward C. Prescott, "The Equity Premium: A Puzzle," Journal of

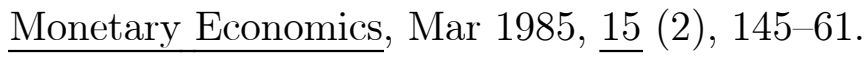

Parker, Jonathan A., "The Consumption Risk of the Stock Market," Brookings Papers on Economic Activity, 2001, 2, 279-348.

- and Christian Julliard, "Consumption Risk and Cross-Sectional Returns," November 2002. Princeton University Manuscript.

Piazzesi, Monika, "Comment on Gabaix and Laibson, 'The 6D bias and the equity premium puzzle'," in Ben Bernanke and Ken Rogoff, eds., N.B.E.R. Macroeconomics Annual 2001, Cambridge: MIT Press 2001.

Rubinstein, Mark, "The Valuation of Uncertain Income Streams and the Pricing of Options," Bell Journal of Economics, 1976, 7, 407-25.

Shiller, Robert J., "Consumption, Asset Markets, and Macroeconomic Fluctuations," Carnegie Mellon Conference Series on Public Policy, 1982, 17, 203-238. 
Vissing-Jorgensen, Annette, "Limited Stock Market Participation." PhD dissertation, Massachusetts Institute of Technology 1998. 


\section{Figure 1: Predicted Excess Return by Risk Aversion and Horizon}

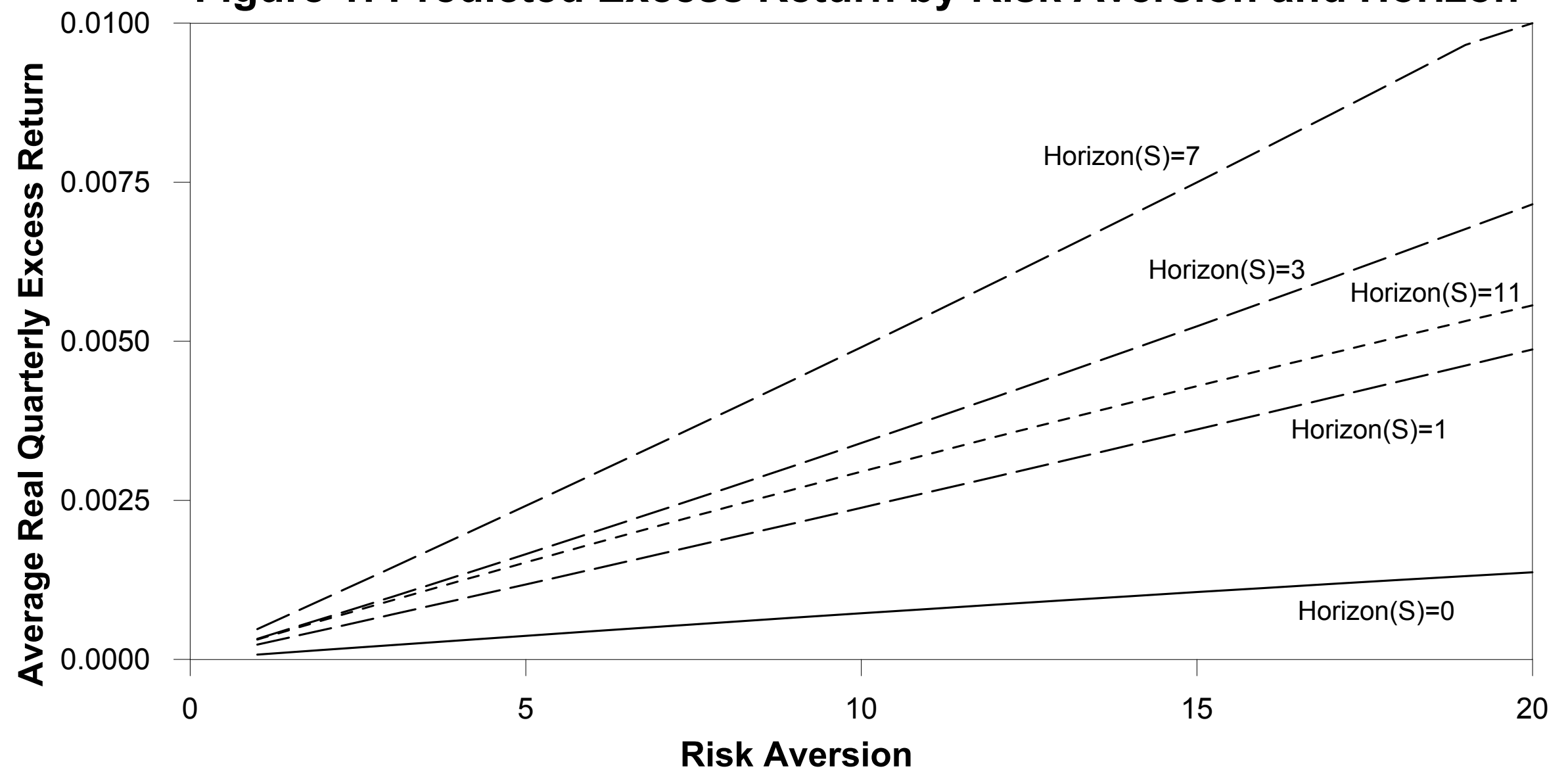


Figure 2: Consumption Risk and Time Variation in Expected Returns


Predicted Returns with Risk Aversion $=5$ 


\section{Figure 3: Average Returns and Consumption Betas}
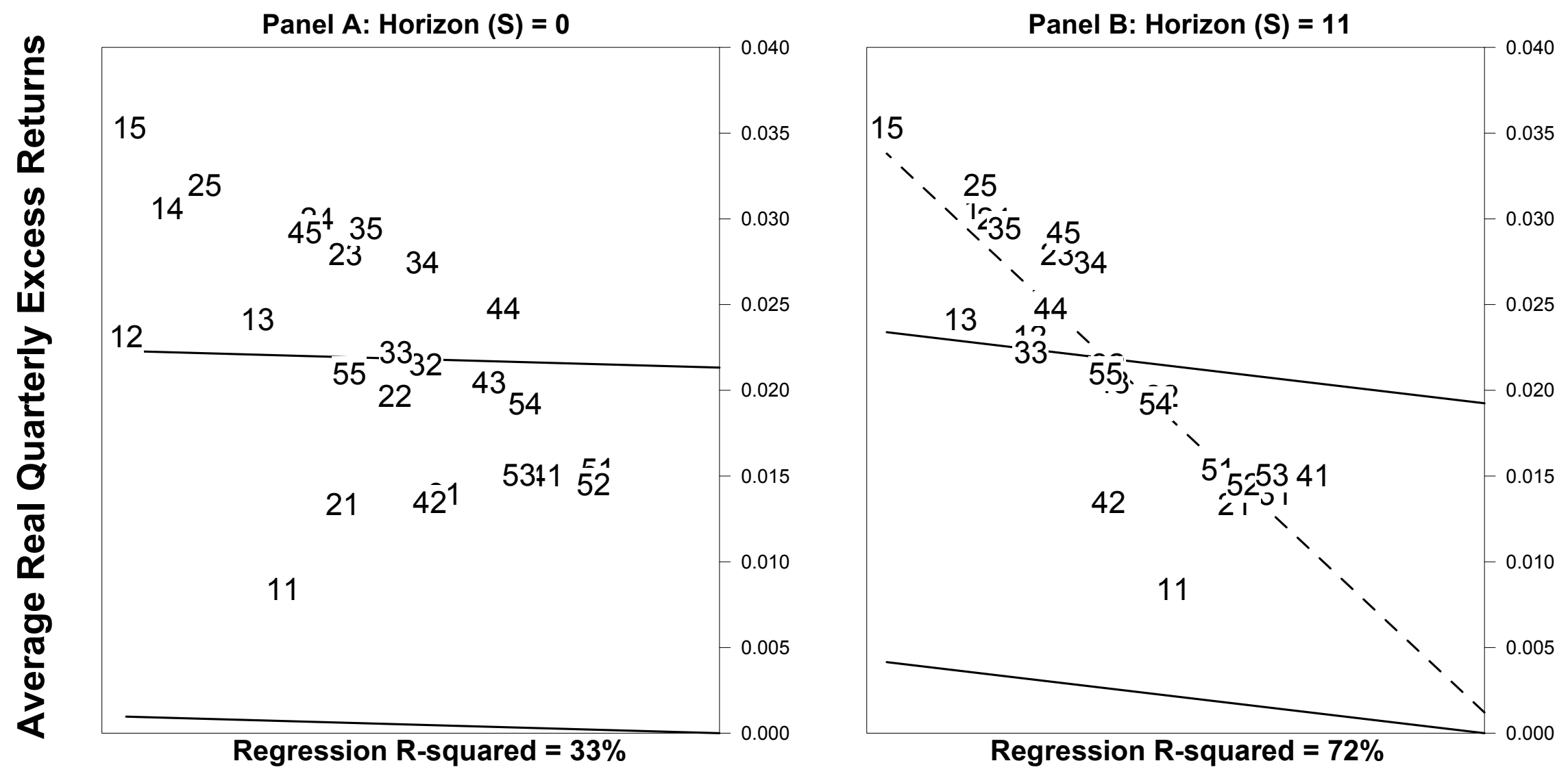

Betas with Risk Aversion $=5$ 